\title{
Responsabilidad estatal del Gobierno Legislador en el marco del covid-19*
}

\author{
Luis Fernando Ulloa Castrillón"*
}

Recibido: 20 de marzo de 2020 • Aprobado: 10 de mayo de 2020

\section{Resumen}

Los estados de excepción por los cuales se decreta la emergencia económica, social y ecológica, para atender una pandemia global como el Covid-19, nos lleva a revisar la capacidad de respuesta que tiene Colombia para conjurar una crisis con repercusiones en el sistema democrático, jurisdiccional y político, en el marco del respeto irrestricto a los derechos humanos, toda vez que el centro de la preocupación para el derecho deriva en la concentración de los poderes públicos en cabeza del ejecutivo, obviando convocar un gran diálogo democrático nacional en el seno del Congreso para revisar y aprobar las salidas a la crisis mediante una legislación especial para estos casos de pandemia, más allá de decretos excepcionales con fuerza de ley de larga duración amparados en normas para cortos periodos, lo que es gravoso para el Estado de derecho, previendo que el Gobierno, en su condición de legislador, abarque muchos temas sin los adecuados controles y sin convocar a todos los poderes representativos del Estado.

Igualmente, se profundizará en el estudio de los derechos fundamentales y los controles, así como la responsabilidad del Gobierno Legislador cuando ostenta supra poderes y finalmente se abordará la imputación objetiva basada en el daño especial en concordancia con los mecanismos de protección de los derechos fundamentales de la cidH y los derechos humanos.

\footnotetext{
El artículo es producto del proyecto de investigación "Responsabilidad estatal del Gobierno Legislador en el marco del Covid-19", gestionado en la Universidad Libre de Colombia.

Citar como: Ulloa Castrillón, L. F. (2020). Responsabilidad estatal del Gobierno Legislador en el marco del Covid-19. Revista IUSTA, 53, 69-105. DoI: https://doi.org/10.15332/25005286.6272

* Magíster en Derecho Administrativo, consultor y asesor en el área de derecho público. Correo electrónico: ferchoulloac@yahoo.com. orcid: 0000-0001-5221-6004.
} 
Palabras clave: responsabilidad estatal, Gobierno Legislador, Covid-19, estados de excepción, decretos legislativos con fuerza de ley.

\title{
State Responsibility of the Legislating Government in the Context of Covid-ig
}

\begin{abstract}
The states of emergency by which an economic, social, and ecological emergency is decreed to address a global pandemic such as Covid-19, lead us to examine the response capacity of Colombia to avert a crisis with repercussions on the democratic, jurisdictional, and political systems. All of this, within the framework of unrestricted respect for human rights, since the main concern of law derives from the concentration of public powers in the executive branch and omitting the convening of a great national democratic dialogue within Congress to review and approve the solutions to the crisis through special legislation for these cases of pandemic, beyond exceptional decrees with long-term force of law protected by rules for short periods, which is burdensome for the rule of law, foreseeing that the Government, as legislator, covers many issues without adequate controls and without convening all the representative powers of the State.

This article examines fundamental rights and controls, as well as the responsibility of the Legislating Government when it holds extra powers, and it finally addresses the objective imputation based on special harm in accordance with the mechanisms for the protection of the fundamental rights of the IACHR and human rights.
\end{abstract}

Keywords: State responsibility, Legislative Government, Covid-19, states of emergency, legislative decrees with force of law.

\section{RESPONSABILIDADE ESTATAL DO GOVERNO LEGISLADOR NO CONTEXTO DA COVID-I 9 \\ Resumo}

Os estados de exceção pelos quais a emergência econômica, social e ecológica é decretada, a fim de atender uma pandemia global como a da covid-19, leva-nos a analisar a capacidade de resposta que a Colômbia tem para remediar uma crise com consequências para o sistema democrático, jurisdicional e político, no âmbito 
do respeito irrestrito aos direitos humanos, sempre que o foco da preocupação com o direito derive na concentração dos poderes públicos liderados pelo Executivo, tornando óbvia a convocação de um grande diálogo democrático nacional no seio do Congresso para revisar e aprovar as possíveis saídas para a crise mediante uma legislação especial para os casos de pandemia, mais além de decretos excepcionais com força de lei de longa duração amparados em normas para curtos períodos, o que é um agravo para o Estado de direito, prevendo que o governo, em sua condição de legislador, abranja muitos temas sem os adequados controles e sem convocar a todos os poderes representativos do Estado. Além disso, aprofunda-se no estudo dos direitos fundamentais e dos controles, bem como da responsabilidade do governo legislador quando ostenta maiores poderes; por último, aborda-se a imputação objetiva baseada no dano especial em concordância com os mecanismos de proteção dos direitos fundamentais da Comissão Interamericana de Direitos Humanos e com os direitos humanos.

Palavras-chave: responsabilidade estatal, governo legislador, covid-19, estados de exceção, decretos legislativos com força de lei.

\section{Introducción}

Sea lo primero referirnos a la institución jurídica denominada estados de excepción que contiene a su vez el estado de guerra exterior, el de conmoción interior y el Estado de emergencia, previstos en la Constitución Política colombiana de 1991, mediante los artículos 212, 213 y 215, respectivamente, y en consecuencia el Gobierno Nacional pasará a desempeñar el papel de Estado legislador para conjurar aquellas crisis de extrema gravedad que requieren medidas de urgencia, inmediatez y de alta complejidad, que no es posible atender con leyes ordinarias que expida el congreso.

Como antecedentes de la declaratoria de Estado de emergencia, se observa que es una institución antigua que, si bien no la contemplan muchos Estados en sus respectivas cartas constitucionales, sí existe en legislaciones especiales para atender las diferentes perturbaciones al orden público o declaratorias de guerra exterior; pero en pocos países se consideraron las emergencias derivadas de circunstancias económicas, ecológicas o por grave calamidad que impactan simultáneamente todo el territorio nacional. En dicha medida, muy pocos Estados en el mundo adoptaron la figura por mandato constitucional, entre tanto, lo más próximo en Latinoamérica 
lo podemos observar en la Constitución de Nicaragua ${ }^{1}$, posteriormente México y El Salvador.

En Colombia, la institución denominada estado de emergencia, decretada cuando se presenten perturbaciones graves al orden económico, social y ecológico, obedece a una evolución que tuvo sus comienzos en 1944, toda vez que la Constitución de 1886, en su artículo 121, consideraba el estado de sitio como único instrumento jurídico para dotar de atribuciones excepcionales al Gobierno con el fin de restablecer material o militarmente el orden público turbado por causa de conmoción interior o guerra exterior. Así mismo, para el tratadista Pérez (2010), las únicas medidas que podían tomarse en virtud de la declaración del estado de sitio debían ser simplemente medidas de "alta policía" o medidas militares, lo que llevó a conjurar las crisis mediante actuaciones de orden público declarando el estado de sitio sin poder atender circunstancias de carácter económico, social, ecológico o grave calamidad pública; "teniendo en cuenta que en la concepción clásica liberal reinante, los fenómenos económicos eran ajenos a los menesteres ordinarios del Estado”.

Posteriormente, a partir de 1944 se empezó a dar una aplicación mucho más amplia al artículo 121 constitucional para conjurar situaciones económicas y sociales, el cual versaba exclusivamente para los efectos de alteración del orden público policivo, y en lo sucesivo se formalizó esta práctica ${ }^{2}$ en la medida que no se contaba con una institución de emergencia exclusiva que llegaría más adelante, gracias a las tesis del jurista y político Darío Echandía ${ }^{3}$ sembradas en el Congreso de la República en 1959, las cuales, a posteriori, arrojaron sus frutos mediante la aprobación del Acto Legislativo n. ${ }^{\circ} 1$ de 1968 cuyo artículo 43 modificó el artículo 122 de la Carta, consagrando el estado de emergencia en la legislación nacional ${ }^{4}$ y que actualmente se erige en el artículo 215 de la Constitución de 1991 (Pérez, 2010).

1 La reformada varias veces Constitución de Nicaragua de 1950 posee una significativa importancia histórica y un referente jurídico latinoamericano en materia de estados de excepción. Mediante su artículo 133, estableció que le "corresponde al poder legislativo en cámaras separadas [...]. 5) Declarar, fijando su duración, el estado general de emergencia económica, cuando así lo exijan las circunstancias anormales del país".

2 Véase la tesis de Inés Cardozo (1972). El estado de emergencia económico y social. Bogotá D.C., Colombia: Universidad Libre de Colombia.

3 Siendo el primer jurista colombiano que esgrimió una posición basada en la noción de orden público económico, muy distante de las instituciones militares preponderantes en la Constitución colombiana de 1886 .

4 El Acto Legislativo 1 de 1968, en su artículo 43, dispuso modificar el artículo 122 de la Constitución Nacional (1886) en los siguientes términos: "cuando sobrevengan hechos distintos de los 
Otro significativo antecedente se presentó en 1979 frente al examen de constitucionalidad ejercido por la Corte Suprema de Justicia, quien se pronunció sobre el conflicto de competencias suscitado entre el Gobierno "legislador" y su eventual usurpación de funciones en desconocimiento de la separación de poderes, con ocasión a la expedición de normas legislativas en virtud del estado de emergencia, en que se dejó por sentado que el ejecutivo solo tiene facultad para afrontar dichas situaciones exclusivas, dejando en manos del legislativo la función ordinaria de aprobar leyes ${ }^{5}$.

Tenemos entonces que el Gobierno cuando hace uso de la institución jurídica denominada estado de emergencia, debe hacerlo a través de los denominados decretos legislativos que el mismo artículo 215 en su parágrafo así los denomina. Por un lado, tenemos una institución jurídica de emergencia creada por la propia Constitución $y$, por otro lado, encontramos los mecanismos por los que ella cobra vida (decretos legislativos). Resta aclarar que el ejecutivo, en uso de esos decretos legislativos, tiene unas limitaciones enmarcadas en que solamente podrán referirse a materias que tengan relación directa y específica con la situación que haya determinado dicha figura, ya que esta delimitación tiene como fin evitar que se desborde en sus facultades usurpando las competencias del poder legislativo, puesto que el temor que se quiere evitar dentro de la arquitectura constitucional es que se use esta vía como un camino sin retorno hacia una dictadura por la cual el poder ejecutivo concentra los poderes de los demás órganos del Estado sin que tenga frenos o controles.

Ya decía Kelsen (2004), mediante su Teoría general del Estado en 1925, que la mayoría de las constituciones, que se fundamentan en el principio de la separación de poderes, nacido de la teoría de Montesquieu, cuyos órganos estatales "fundamentalmente independientes", se trastocan cuando se autoriza al jefe del poder ejecutivo a expedir normas generales mediante una "ley otorgadora de facultades" (Ermächtigungsgesetz), cuando se presentan circunstancias especiales, tales como una guerra, una rebelión o una crisis económica, en lugar de que sea el órgano legislativo quien las expida. El puro principio de la división del poder no solo se traduce en

previstos en el artículo 121, que perturben o amenacen perturbar en forma grave e inminente el orden económico o social del país o que constituyan también grave calamidad pública”.

5 Véase la Gaceta Oficial n. 2401 de 1979 de la Corte Suprema de Justicia. http://www.cortesuprema. gov.co/corte/wp-content/uploads/subpage/GJ/Gaceta\%20Judicial/GJ\%20CLX\%20n.\%202401\%20 (1979).pdf 
la división de varias funciones, sino que reparte una función entre varios órganos, teniendo por efecto una disminución del poder.

Conforme a lo anterior, nos preguntamos sobre la responsabilidad del Estado por aquella producción normativa en cabeza del poder ejecutivo cuando en ejercicio de su competencia para proferir normas con rango legal en estados de emergencia se extralimitan, usurpan o restringen severamente los derechos constitucionales, fundamentales y los derechos humanos de los ciudadanos, que debe salvaguardar.

Partiendo de la base sobre la cual debemos distinguir entre los problemas jurídicos sustanciales y aquellos institucionales que derivan del marco legal de emergencia por la declaratoria de estados excepcionales, se puede colegir, bajo el supuesto de que la institucionalidad del país pasa por la conformación de un ordenamiento jurídico equilibrado y estructurado mediante un orden jerarquizado. Esto lleva a delimitar la configuración del sistema normativo colombiano que se base en la constitución política situada en la cúspide del ordenamiento jurídico político nacional, como lo propondría lustros antes Hans Kelsen en su obra, que puede ser sujeto a reformas denominadas actos legislativos, tramitados por el Congreso de la República, donde dichos actos son objeto de control de constitucionalidad por parte de la Corte Constitucional. También encontramos que el Congreso naturalmente aprueba leyes en sentido formal con el concurso del poder ejecutivo mediante la sanción presidencial, las cuales deben estar sujetas al control de constitucionalidad por parte de la Corte Constitucional (Hoyos, 2020).

Es de recordar que para Kelsen la teoría de legalidad de la norma corresponde a deducir que la norma de superior jerarquía (la proferida por el parlamento) legitima una de inferior jerarquía (decretos proferidos por el ejecutivo). Entonces toda norma de superior escalafón jerárquico se constituye como una regla de orden formal o material, que tiene la facultad de crear nuevas normas de orden inferior. Pero si la creación de normas de ambos grados está concentrada en una sola mano, como en las autocracias primitivas, en las que el monarca establece las normas generales y decide los casos particulares sobre la base de aquellas, existe el peligro de que no se atenga estrictamente a la norma general por él mismo creada al resolver un caso concreto, y piense que puede modificarla en todo tiempo a su arbitrio. De ese modo peligran la legalidad de la ejecución y, en relación con la seguridad jurídica, la previsibilidad de esta (Kelsen, 2004).

Posteriormente, debemos hacer énfasis en los decretos que expide el poder ejecutivo, que en el marco de los estados de excepción pasan a denominarse "decretos 
legislativos" que tendrán el mismo peso normativo de los decretos con fuerza de 1 ey ${ }^{6}$, siempre y cuando cumplan con los presupuestos formales y materiales que se le exigen. Pero es precisamente aquí donde estriba el problema que se afronta en materia de preservar el orden jurídico institucional, puesto que el Gobierno Nacional también expide decretos ordinarios o reglamentarios (de los decretos legislativos) trayendo consigo un álgido debate entre los juristas y doctrinantes, los constitucionalistas y administrativistas, en el entendido de que no se aprecia claramente cuál sería la institución facultada para realizar el control judicial; bien sea un control de constitucionalidad por parte de la Corte Constitucional o si se requiere un control de legalidad ante el Consejo de Estado. No es pacífica la resolución de la situación, puesto que dichos decretos (de naturaleza ordinaria en primera medida) generalmente cruzan la delgada línea de restricción de los derechos y libertades fundamentales de los ciudadanos, entiéndase libertad de reunión, de locomoción, cierre de establecimientos de comercio, entre muchas otras materias, las cuales deben ser consideradas como leyes en sentido material cuyo control debe recaer sobre la Corte Constitucional (Palacios, 2020).

Los decretos ordinarios o los decretos reglamentarios del orden nacional, surten su control de legalidad ante el Consejo de Estado, y cualquier ciudadano puede ejercer el derecho de demandarlos cuando los considere ilegales o cuando lo afecten en sus derechos o le causen daños antijurídicos, bien sea por acción u omisión bajo la cláusula de responsabilidad estatal consagrada en el artículo 91 de la Carta colombiana; en igual sentido, se tiene la garantía de controvertir la presunta legalidad de las medidas tomadas en los órdenes departamental y municipal accionando las entidades territoriales ante la jurisdicción administrativa según su competencia por factor territorial. De igual forma lo establecen los artículos $51 \mathrm{y}$ 52 de la Ley Estatutaria 137 de 1994, "por la cual se regulan los estados de Excepción en Colombia", en la medida que el "Estado será siempre responsable por los excesos en la utilización de las facultades previstas en la presente ley, sin perjuicio de la responsabilidad civil, penal o disciplinaria que corresponda a los servidores públicos” (Ley 137 de 1994, art. 51).

La misma ley estatutaria hace responsable al poder ejecutivo en funciones de legislador frente a una falta de control político en materia de derechos humanos y las libertades fundamentales que pone en cabeza de la Cámara de Representantes

6 Conforme lo establece el artículo 215, del capítulo 6, título VII de la Carta, en cuanto sean declarados los estados de excepción. 
(Ley 137 de 1994, art. 52); de igual modo, establece que en el ejercicio del estado de excepción no le es dado al ejecutivo legislador afectar el régimen de legalidad del Estado de derecho, es decir, que no puede comentar arbitrariedades, máxime si están en juego las garantías fundamentales de los ciudadanos (Ley 137 de 1994, art. 7). Igualmente, queda rotundamente prohibido, para el Gobierno Legislador, suspender los derechos humanos, las libertades fundamentales, interrumpir el normal funcionamiento de las ramas del poder público, de los órganos del Estado, suprimir o modificar los organismos o las funciones básicas de acusación y Juzgamiento (Ley 137 de 1994, art. 15).

Igualmente, la referida norma exhorta al Gobierno Legislador a informar a los organismos internacionales: Organización de Estados Americanos (ozA) y Organización de Naciones Unidas (ONU) ${ }^{7}$ sobre los motivos que condijeron al Gobierno a decretar los estados de excepción y las circunstancias legislativas que limiten el ejercicio de derechos, conforme el artículo 27 de la Convención Americana de los Derechos Humanos y el artículo $4^{\circ}$ del Pacto Internacional de Derechos Civiles y Políticos. En igual sentido, se ordena a cumplir un papel relevante protagonizado por la Cámara de Representantes mediante las comisiones legales de derechos humanos, convocadas para velar por el cumplimiento de las disposiciones que deben proteger en todo momento los derechos humanos y las libertades fundamentales, y promover las investigaciones pertinentes ante las autoridades correspondientes (Ley 137 de 1994, art. 52).

No se puede pretender que unos decretos ordinarios pasen a tener la connotación de naturaleza legislativa por el solo hecho de expresar en su parte considerativa una norma declaratoria de emergencia. No le es dado al legislador excepcional romper la unidad de materia ni su sentido material por principio de primacía de la materia sobre lo formal, pues aunque estas aparenten indicar que son decretos legislativos por cuanto son conexos a la declaratoria del estado de emergencia, no los es en su contenido material; en igual sentido, "no son reglamentarios de ninguna ley como deben de ser los decretos ordinarios sino que restringen libertades y derechos por

Se deberá enviar una comunicación al secretario general de la Organización de Estados Americanos y al secretario general de las Naciones Unidas al día siguiente de la declaratoria del estado de excepción, informándoles a los Estados partes de los tratados citados sobre la declaratoria de los estados de excepción con los motivos que condujeron a tomar dicha declaratoria. Igual comunicación deberá enviarse cuando sea levantado el estado de excepción (Ley 137 de 1994, art. 16). 
la perturbación del estado Económico, Social y Ecológico en razón del Covid, materia exclusiva de un Decreto Ley” (Garzón, 2020, p. 45) ${ }^{8}$.

\section{E1 Covid-19 en la legislación nacional}

Entonces, reiteramos que no es pacífica la tensión suscitada, bajo el entendido de que el Gobierno Nacional declaró el estado de emergencia económica, social y ecológica en todo el territorio nacional en virtud de los decretos legislativos 417 del 17 de marzo de 2020 y posteriormente el 637 del 6 de mayo de 2020, los cuales habilitaron la expedición de los decretos (ordinarios) $457 \mathrm{del} 22 \mathrm{de}$ marzo, $531 \mathrm{del}$ 8 de abril, 539 del 24 de abril, 636 del 6 de mayo, 689 del 22 de mayo, 749 del 28 de mayo, por medio de los cuales se ordenó el "aislamiento preventivo obligatorio" como medida de emergencia sanitaria para atender la pandemia del Covid-19, que se viene prorrogando desde el 25 de marzo hasta el $1 .^{\circ}$ de julio de $2020^{9}$.

Así las cosas, es sumamente preocupante pensar que se regulen absolutamente todas las medidas en materias fundamentales del Estado social de derecho sin pasar por el cedazo de la discusión democrática del Congreso como lo determinan las cláusulas pétreas del ordenamiento constitucional. Por ello, observamos que dichos decretos restringen derechos fundamentales por vía ordinaria mediante el confinamiento, la cuarentena y el aislamiento social, siendo considerado como "una grave equivocación”, en la medida que esta disposición legislativa se constituye como el centro de conexidad entre el objeto material a proteger y la declaratoria de emergencia que adopta el Gobierno para tratar de conjurar la crisis del Covid-19, es decir, que asocia directamente la protección del derecho a la vida con la cuarentena que deben afrontar los ciudadanos, "pero además es la medida que restringe de manera más grave muchos derechos como la libertad de movimiento, libertad

8 Igualmente, nos plantea la imperiosa necesidad de contar con garantía para el sistema de derechos fundamentales, los cuales hacen parte de la arquitectura constitucional en la medida que accionan los frenos y contrapeso de nuestro sistema democrático, pues al ser unos decretos ordinarios y no decretos ley aquellos que restringen libertades fundamentales de los ciudadanos, se sienta un precedente peligroso en la institucionalidad del país, sobre lo que se debe prestar exacerbada atención en busca de los mecanismos jurídicos para que se tenga un control constitucional con observancia internacional en materia de derechos humanos, sociales y fundamentales.

9 Se aclara que esta fecha se apunta en el presente documento, por cuanto es la fecha de corte en la elaboración del presente trabajo. 
de circulación, derechos de naturaleza económica, social, trabajo, libre iniciativa privada" (Hoyos, 2020).

En materia de grave calamidad pública, que es el presupuesto esencial en el cual se sustenta la adopción de las medidas excepcionales, tenemos por aclarar que las medidas de emergencia para atender la pandemia del Covid-19 exigen la existencia de unos presupuestos tales como: que sobrevengan hechos distintos a la guerra exterior o conmoción interior ${ }^{10}$ que perturben o que amenacen con perturbar en forma grave el orden económico, social y ecológico del país; o que dichos hechos constituyan grave calamidad pública. Precisamente en el entendido de legislar especialmente para conjurar las causas y efectos de una calamidad, la doctrina nos enseña que si bien la declaratoria de dicha emergencia conlleva un "desequilibrio de los factores de la vida económica, social y ecológica del país capaz de producir una alteración de tal magnitud que la comunidad se ve alterada en los elementos que aseguran su propia existencia y armonía social”, también debe establecer la existencia del desequilibrio en la ecuación que tiene que ponderar dichos hechos calificados como graves para el campo económico, social y ecológico.

Al paso de esta interpretación, tenemos que el tratadista Jacobo Pérez (2010) refiere acerca de la existencia del presupuesto de calamidad pública que, si esta se presenta, su declaratoria debe observar que no basta con que sea cualquier calamidad pública convencional, como epidemias, inundaciones o terremotos, por cuanto esta debe ser calificada como grave, lo que significa "que ponga en peligro evidente la existencia actual y futura de la vida, de la comunidad colombiana"; y al respecto nos da mayor claridad la Ley $1523^{11}$ del 24 de abril de 2012, por la cual

10 El artículo 213 constitucional hace referencia a la declaratoria del estado de conmoción interior que se presenta "en caso de grave perturbación del orden público que atente de manera inminente contra la estabilidad institucional, la seguridad del Estado, o la convivencia ciudadana, y que no pueda ser conjurada mediante el uso de las atribuciones ordinarias de las autoridades de Policía, el Presidente de la República, con la firma de todos los ministros, podrá declarar el Estado de Conmoción Interior, en toda la República o parte de ella, por término no mayor de noventa días, prorrogable hasta por dos períodos iguales, el segundo de los cuales requiere concepto previo y favorable del Senado de la República”.

11 La Ley 1523 del 24 de abril de 2012, "Por la cual se adopta la política nacional de gestión del riesgo de desastres y se establece el Sistema Nacional de Gestión del Riesgo de Desastres y se dictan otras disposiciones", estable en sus artículos 58 y 59 los términos de la calamidad pública, según se muestra en los dos siguientes artículos.

Artículo 58. "Calamidad pública. Para los efectos de la presente ley, se entiende por calamidad pública, el resultado que se desencadena de la manifestación de uno o varios eventos naturales o antropogénicos no intencionales que al encontrar condiciones propicias de vulnerabilidad en las personas, los bienes, la infraestructura, los medios de subsistencia, la prestación de servicios o los 
se adopta la política nacional de gestión del riesgo de desastres, que establece en su artículo 4, numeral 5, que la calamidad pública se entiende como:

El resultado que se desencadena de la manifestación de uno o varios eventos naturales o antropogénicos no intencionales que al encontrar condiciones propicias de vulnerabilidad en las personas, los bienes, la infraestructura, los medios de subsistencia, la prestación de servicios o los recursos ambientales, causa daños o pérdidas humanas, materiales, económicas o ambientales, generando una alteración intensa, grave y extendida en las condiciones normales de funcionamiento de la población, en el respectivo territorio, que exige al distrito, municipio, o departamento ejecutar acciones de respuesta, rehabilitación y reconstrucción.

Cuando se observan dichos hechos notorios que llevan a la administración a la declaratoria de una emergencia, se está ante la situación de un acto eminentemente político que debe materializarse en expresiones jurídicas, lo cual se cumple elaborando un decreto por parte del Gobierno Nacional en virtud del cual debe observar los requisitos formales que exhorta la Constitución Política, como son: la firma de todos los ministros; que contenga una motivación con todos aquellos presupuestos fácticos, valorativos y justificaciones que llevaron al poder ejecutivo a expedir un decreto legislativo que adopte medidas generales para conjurar la crisis y evitar la extensión de sus efectos devastadores; también debe señalar expresamente

recursos ambientales, causa daños o pérdidas humanas, materiales, económicas o ambientales, generando una alteración intensa, grave y extendida en las condiciones normales de funcionamiento de la población, en el respectivo territorio, que exige al distrito, municipio, o departamento ejecutar acciones de respuesta, rehabilitación y reconstrucción”.

"Artículo 59. Criterios para la declaratoria de desastre y calamidad pública. La autoridad política que declare la situación de desastre o calamidad, según sea el caso, tendrá en consideración los siguientes criterios:

1. Los bienes jurídicos de las personas en peligro o que han sufrido daños. Entre los bienes jurídicos protegidos se cuentan la vida, la integridad personal, la subsistencia digna, la salud, la vivienda, la familia, los bienes patrimoniales esenciales y los derechos fundamentales económicos y sociales de las personas; 2 . Los bienes jurídicos de la colectividad y las instituciones en peligro o que han sufrido daños; 3. Entre los bienes jurídicos así protegidos se cuentan el orden público material, social, económico y ambiental, la vigencia de las instituciones, políticas y administrativas, la prestación de los servicios públicos esenciales, la integridad de las redes vitales y la infraestructura básica; 4. El dinamismo de la emergencia para desestabilizar el equilibrio existente y para generar nuevos riesgos y desastres; 5. La tendencia de la emergencia a modificarse, agravarse, reproducirse en otros territorios y poblaciones o a perpetuarse; 6 . La capacidad o incapacidad de las autoridades de cada orden para afrontar las condiciones de la emergencia; 7. El elemento temporal que agregue premura y urgencia a la necesidad de respuesta; 8. La inminencia de desastre o calamidad pública con el debido sustento fáctico”. 
el término de duración en que el ejecutivo hará uso de dichas facultades excepcionales, y finalmente se exige que se convoque al Congreso bajo el presupuesto de control político, quien debe pronunciarse sobre la conveniencia y oportunidad de las medidas adoptadas por el Gobierno.

Nos corresponde señalar, según lo observado por el profesor Jorge Roa (2020), que una de las circunstancias de mayor significación en el caso del coronavirus a nivel global estriba en que se han declarado estados de excepción en todos aquellos países que cuentan con dicha institución jurídica, entre tanto, donde no existe se han amparado en las normas tendientes a conjurar crisis o emergencias; pero los Estados que no cuentan con ninguna figura especial están forzados a prever legislación ad hoc para promulgar leyes especiales. Lo que lleva a un revestimiento mayor en los poderes otorgados al ejecutivo, por el cual se ha concentrado más poder en el presidente. "Allí donde el presidente no concentraba tantos poderes, ahora se encuentran concentrados y en aquellos países que ya tenían absolutamente desequilibrada la ecuación democrática, los poderes del presidente se han mega concentrado", lo que implica que los Estados deben enfrentar la crisis con un desequilibrio en sus ecuaciones democráticas.

Pese a lo anterior, y con ocasión de la atención a la crisis desde la perspectiva jurídica, lo que más preocupa a la academia y a la doctrina estriba en que la declaratoria de cuarentena, confinamiento o aislamiento social no cuenta con antecedentes en el país, ya sea por su condición de inédito y sin consecuencias jurisprudenciales o estudios doctrinales ni evoluciones científicas, lo más próximo que podemos encontrar sería el Código Sanitario Nacional consagrado mediante la Ley 9 de $1979^{12}$ que regula el aislamiento o internación de personas con certificado médico y para grupos específicos de personas que pueden causar riesgo a la comunidad, pero el Gobierno no la citó en su debida oportunidad dentro de los considerandos de los decretos legislativos como fundamento jurídico, por lo que la hace inconstitucional (Uprimny, 2020).

12 El artículo 591 de la Ley 9 de 1979 (Código Sanitario Nacional) establece que para "los efectos del Título VII de esta Ley son medidas preventivas sanitarias las siguientes: a) El aislamiento o internación de personas para evitar la transmisión de enfermedades. Este aislamiento se hará con base en certificado médico expedido por la autoridad sanitaria y se prolongará sólo por el tiempo estrictamente necesario para que desaparezca el peligro de contagio". 


\section{Controles de la actividad legislativa de emergencia}

\section{Del control político}

Le corresponde al Congreso de la República ejercer el control político de los decretos legislativos proferidos por el Gobierno en virtud de la cláusula constitucional 215, mediante la cual se exige del poder legislativo que examine las causas que determinaron el estado de emergencia en concordancia con las medidas adoptadas por el ejecutivo según criterios de conveniencia y oportunidad, siempre conservando la institucionalidad del país, aplicando los frenos y contrapesos que balancean los poderes estatales, para retomar el curso de aquellas normas que puedan afectar la vida democrática del Estado social de derecho, y en materia de derechos humanos y garantías fundamentales le confiere un papel relevante a la Cámara de Representantes para que mediante las Comisiones Legales de Derechos Humanos sean adelantados los controles respectivos para velar por el cumplimiento de las disposiciones que deben proteger en todo momento los derechos humanos $\mathrm{y}$ las libertades fundamentales, y promover las investigaciones pertinentes ante las autoridades correspondientes ${ }^{13}$.

Es de competencia del órgano legislativo que ejerza sus funciones mediante un debate democrático frente a la permanencia en el tiempo de dichas medidas o, por el contrario, que las derogue, modifique o adicione conforme sus facultades constitucionales; competencias que también conllevan el juicio de responsabilidad política y jurídica que le asiste al Gobierno cuando se evidencien extralimitaciones en sus facultades, abusos en el poder o indebida injerencia de competencias; así como las omisiones en su actividad cuando debía hacerlo, haciéndolo merecedor de una responsabilidad por inactividad del Estado legislador.

Lo anterior, con énfasis en la responsabilidad del Estado legislador, nos deja un lánguido desaliento cuando no se observa que la rama legislativa comparezca a un juicio de responsabilidad por el hecho de la ley; ahora, menos aún va a comparecer un Gobierno Legislador, que debería tener mayor esfera de responsabilidad, mayor control judicial y político, y que debería obrar con mayor escrúpulo y precaución cuando es conciente de que concentra la mayoría de los poderes públicos en él.

13 Véase art. 52 de la Ley Estatutaria 137 de 1994, "por la cual se regulan los Estados de Excepción en Colombia". 
En época de aislamiento, cuarentena, confinamiento, distanciamiento social o demás medidas que este viene tomando para que sea exclusivamente el ejecutivo quien actúe en medio de la pandemia, el país espera una respuesta activa en el control social por parte de los ciudadanos, donde se ejerzan acciones de constitucionalidad y acciones de control interpuestas ante la jurisdicción contencioso administrativa.

\section{Control de constitucionalidad en el Estado social de derecho}

Es de recordar que el propio parágrafo del artículo 215 de la carta colombiana establece que el Gobierno enviará a la Corte Constitucional al día siguiente de su expedición los decretos legislativos que dicte en uso de las facultades a que se refiere este artículo, para que aquella decida sobre su constitucionalidad. Si el Gobierno no cumpliere con el deber de enviarlos, la Corte Constitucional aprehenderá de oficio y en forma inmediata su conocimiento. Esto en virtud del control de constitucionalidad que debe surtirse. Y aquí es donde empezamos a revisar el control judicial de estas polémicas normas (Pérez, 2010).

Por lo visto, el mandato de la carta política dispone que la Corte Constitucional realice el control automático de constitucionalidad sobre las normas de naturaleza legal expedidas por el Congreso e igualmente avoque conocimiento sobre los decretos legislativos, o decretos con fuerza de ley. Para aquellos decretos de naturaleza ordinaria o reglamentaria, se realizará el control inmediato de legalidad por parte del Consejo de Estado, respectivamente.

Es de recordar que la ley estatutaria que regula los estados de excepción insta que en ningún caso se podrá afectar el núcleo esencial de los derechos fundamentales con el fin de conservar la vigencia del Estado de derecho, puesto que dicha institución está sometida al régimen de legalidad y, por lo tanto, quien la invoque, siendo el caso del ejecutivo, no podrá cometer arbitrariedades so pretexto de su declaración. Cuando los derechos o libertades fundamentales se vean restringidos mediante decretos legislativos reglamentarios sustentados en estados de excepción, estos no podrán afectar el núcleo esencial de tales derechos y libertades (Ley 137 de 1994, art. 7) y, en tal sentido, los decretos legislativos en todo caso deberán demostrar una justificación expresa de los motivos por los cuales se impone cada una de las limitaciones de los derechos constitucionales de tal manera que permitan demostrar la relación de conexidad con las causas de la perturbación y los motivos por los cuales se hacen necesarias (Ley 137 de 1994, art. 8). 
En consecuencia, se deben reforzar los controles en medio de la actual pandemia por cuanto se está legislando para que todas las actividades se realicen en confinamiento y desde las instancias de domicilio, lo que puede causar riesgos en las formalidades de dichos controles realizados por medios virtuales. La observancia de las reglas procesales en la confección del formalismo legal, bien sea para aprobar, revisar o juzgar las normas expedidas por el ejecutivo debe contar con la mayor cautela y diligencia por parte del poder legislativo y judicial, puesto que en ejercicio del trabajo virtual desde casa, el trabajo remoto, el teletrabajo y demás flexibilidades que se están permitiendo mediante las nuevas normas, se puede poner en riesgo la actividad de control, es decir, en aspectos tan relevantes del formalismo como las aprobaciones, la convocatoria a sesiones, el quorum, el reparto, las deliberaciones, consensos, la publicidad, audiencias entre otros muchos aspectos que el Congreso y la jurisdicción deben asumir con pies de plomo (Agudelo, 2020).

Lo único que sabemos a ciencia cierta es que la crisis del Covid-19 llegó para quedarse, como lo afirman los expertos, entre los que se cuentan los epidemiólogos y la Organización Mundial de la Salud, según el informe de las Naciones Unidas y Fronteras 2016 (onu, 3 de abril de 2020), y no tenemos certeza científica de cuánto tiempo tardará en controlarse. Si eso es lo único certero que tenemos, entonces lo más sensato e inteligente que podemos hacer como Estado es no improvisar en normas de día a día y, por el contrario, convocarnos en un gran diálogo nacional desde el epicentro del corazón democrático y legislativo en cabeza del Congreso para acordar un gran marco legislativo, un código de atención a las pandemias, que, en palabras del profesor Uprimny (2020), se denominaría el "Marco Jurídico Para las Pandemias", en el entendido de que se concibe como un marco legislativo completo, a manera de código nacional, que permita mayor movilidad a los actores de la academia, el cuerpo científico y el cuerpo político en armonía con el jurisdiccional y en acatamiento de los preceptos internacionales de los tratados en materia de derechos fundamentales.

En la medida que la interpretación del derecho no puede ser aislada de las realidades nacionales, cuyas consecuencias deben observarse según su proporcionalidad conforme los mandatos de optimización ${ }^{14}$ de los principios mediante el examen de constitucionalidad, por cuanto dicha institución podría establecer cuál es el

$14 \quad$ El mandato de optimización basado en los principios que representan la ponderación de derechos entendidos como la realización de estos según sus posibilidades normativas y fácticas (Velázquez Zimmerling, 2007). 
marco normativo de las pandemias, para atribuirle un carácter de norma legislativa extraordinaria y posteriormente remitirla al Congreso para que establezca un marco legislativo especial de atención a las pandemias, ello era lo que inicialmente debía haber hecho el Gobierno Nacional, por cuanto se requiere, en primer orden, "construir un Marco Jurídico para las Pandemias y luego decretar el aislamiento obligatorio. Como no lo hizo, lo mejor es ejercer una remisión al control automático de la Corte por considerarlos materialmente legislativos", lo cual sería armónico con la jurisprudencia, en el sentido de conocer, por competencia constitucional, aquellas normas de contenido material de ley (Uprimny, 2020).

Para el profesor Roa (2020), el examen de constitucionalidad debe contar con la plena observancia de los enfoques democrático (abusos), científico (principio de precaución y prevención) y humanitario (grupos vulnerables) en el marco de los derechos humanos y las garantías fundamentales, así:

- Democrático. Verificar que el Gobierno Legislador no concentre tanto poder que pueda conllevar la usurpación de competencias en detrimento de la autonomía administrativa, funcional y territorial ${ }^{15}$. En igual sentido, se debe evitar la elusión constitucional ${ }^{16}$; la prevención del blanqueo ${ }^{17}$, garantizando el Estado social de derecho con pleno respeto por los derechos humanos y fundamentales ${ }^{18}$. Así las cosas, la Corte puede juzgar omisiones legislativas cuando los decretos no han cubierto todas las necesidades o no han tenido en cuenta todos los factores que permiten conjurar la crisis.

- Cientifico. Aduce que las medidas adoptadas para la superación de la crisis deben contar con el principio de precaución respaldado científicamente ${ }^{19}$.

15 Se comprende las entidades territoriales (departamentos y municipios), aquellas entidades o instituciones del orden nacional, departamental o municipal.

16 Controlar que los decretos legislativos no reformen la Constitución o elementos que requieran reserva de ley estatutaria o ley orgánica.

17 Entendida como la coherencia presentada entre el decreto reglamentario frente al decreto legislativo original, evitando que las normas derivadas del estado de excepción no permanezcan per secula seculorum, toda vez que estas tienen estrictos términos de vigencia entre tanto perdure la calamidad. De aquí que surja la responsabilidad del legislador al establecer impuestos y tributos en detrimento de los derechos laborales y sociales de los trabajadores públicos del país, circunstancia inadmisible en las precarias condiciones que afrontamos en medio de una pandemia (Agudelo, 2020).

18 Garantizando que las medidas adoptadas sean necesarias, proporcionales, temporales y que sean idóneas.

19 En igual sentido, el ejecutivo debe entender que no puede permitirse un distanciamiento entre la política y la ciencia, estas deben estar coordinadas con los científicos y atendiendo los lineamientos de los expertos (Agudelo, 2020). 
- Humanitario. Garantizar los derechos de aquellas personas que se encuentran en situación de debilidad social y económica, a quienes normalmente este tipo de situaciones les profundiza su malestar ${ }^{20}$. Igualmente, este enfoque sirve de puente para que se garanticen los derechos fundamentales y los derechos humanos in extensu.

Así mismo, los decretos legislativos no pueden suspender los derechos humanos y fundamentales, $\mathrm{y}$, en caso de tensión entre unos y otros, se debe dirimir garantizando siempre estos, en especial, los más susceptibles de ser severamente restringidos hasta el punto de llegar a una suspensión como la vida, la movilidad, la locomoción, la salud, el trabajo, libertad de empresa, y aquellas actividades que mantienen la salud tanto económica como social de los ciudadanos. Los considerandos deben estar motivados sobre los tratados internacionales en conexidad con los postulados constitucionales de la carta colombiana (Agudelo, 2020).

Lo anterior se viene abordando mediante la hermenéutica, en la medida que se viene acuñando la aplicación diferenciada de derechos, toda vez que pueden ser constitucionales algunas conductas que restringen a un sector determinado, lo que se ha visto mediante la propuesta del Gobierno cuando permite el desconfinamiento de manera inteligente, lo que lleva a una restricción de derechos sobre algunos sectores de la sociedad por condiciones horarias, haciendo uso de la teoría de la aplicación diferenciada de derechos. Así mismo, se puede acudir al instrumento interpretativo de mayor severidad que la jurisprudencia trae para algunos casos que requieren de la técnica de la ponderación, la cual involucra un extremismo deliberado para resolver los conflictos entre derechos al preferir uno sobre el otro, acatando el mandato de optimización constitucional del profesor Robert Alexy ${ }^{21}$, verbigracia lo decretado por el Gobierno cuando restringe la movilidad, la libre circulación, el derecho fundamental de reunión y desplazamiento libre para proteger el derecho a la vida (Velandia, 2020).

20 La Corte debe vigilar la situación de personas especialmente excluidas y vulnerables y que carecen de representación. Entre los grupos poblacionales como las personas privadas de la libertad, las víctimas de la violencia, las mujeres víctimas de violencia intrafamiliar, niños, migrantes, etc.

21 La exigencia de optimización como principio y no como simple regla, en tanto que los principios son normas que requieren que algo sea realizado en la mayor medida de lo posible, dadas sus posibilidades normativas y fácticas (Velázquez y Zimmerling, 2007). 


\section{Los derechos fundamentales en la Constitución de 1991}

La carta constitucional señala, mediante su artículo 2, que es fin del Estado garantizar la efectividad de los principios, derechos y deberes fundamentales, asegurar la convivencia pacífica y la vigencia de un orden justo; y proscribe su suspensión incluso durante los estados de excepción. Así mismo, fue voluntad del constituyente imprimirle la más alta fuerza normativa a una concepción ética del ejercicio del poder, según la cual nada está por encima del respeto y garantía de los derechos humanos y las libertades fundamentales, ni siquiera en los estados de excepción, resaltando que "E1 Estado juez debe interpretar el derecho siempre a través de la óptica de los derechos fundamentales" (Sentencia, C-587/92).

Del análisis de los decretos legislativos y su desarrollo ordinario se percibe un espíritu más finalista que otra cosa, pero recordemos que en derecho no todo vale y esta desviación de poder para conseguir los fines sin importar el sacrificio de los demás derechos es contraproducente, inconstitucional e ilegítima. Así es como el ordenamiento jurídico interno, apoyado en líneas jurisprudenciales, cuenta con instrumentos de interpretación constitucional en respuesta a la colisión de derechos fundamentales, primando su armonización y convivencia pacífica.

En iguales trazas argumentativas, el profesor Agudelo (2020) se refiere a que el ejecutivo debe ser consciente de que también es responsable de la adopción del test de proporcionalidad que aplica la Corte, pero que no es de su exclusividad, por cuanto el Gobierno debe observar los criterios de proporcionalidad, razonabilidad y coherencia con los fines constitucionales, en el marco de los principios de finalidad, necesidad, proporcionalidad, motivación y que se den las condiciones y requisitos del precepto jurídico para la legislación por excepcionalidad.

Tenemos, entonces, que la política que parece ser que se está implementando por parte del Gobierno para conjurar la actual pandemia se distancia de los postulados que determina la Constitución Política y la Ley 137 de 1994 o estatutaria de los estados de excepción ${ }^{22}$, la cual mediante su artículo 15 prohíbe la suspensión

$22 \quad$ La Ley 137 de 1994 establece lo siguiente en materia de derechos fundamentales: "Artículo 5. Prohibición de suspender derechos. Las limitaciones a los derechos no podrán ser tan gravosas que impliquen la negación de la dignidad humana, de la intimidad, de la libertad de asociación, del derecho al trabajo, del derecho a la educación de la libertad de expresión y de los demás derechos humanos y libertades fundamentales que no pueden ser suspendidos en ningún Estado de Excepción. Tampoco podrán ser suspendidas las garantías judiciales indispensables para la protección de tales derechos. De todas formas se garantizarán los derechos consagrados en el artículo 29 de la Constitución Política”. 
de los derechos humanos, las libertades fundamentales, o que se interrumpa el normal funcionamiento de las ramas del poder público o de los órganos del Estado, y que nunca se lleguen a suprimir o modificar los organismos o funciones básicas de acusación y juzgamiento estatales.

En este mismo sentido, la norma dispone que mediante los estados de excepción "no se pueden afectar el núcleo esencial de los derechos y libertades"23, siendo de obligatorio cumplimiento informar a los organismos internacionales ${ }^{24}$ en derechos fundamentales, acatando los instrumentos internacionales como la Resolución 01 del 2020 expedida por la Comisión Interamericana de Derechos Humanos para atender la actual pandemia, lo cual explica la profesora Andrea Garzón (2020) en el siguiente orden:

1. La restricción de las libertades siempre debe motivarse, ya que puede ser ilegítimo en términos políticos e inconstitucional en términos jurídicos decisiones tomadas sin un proceso que vele la aplicación de frenos y contrapesos.

2. No puede tomarse cualquier medida, no todo vale para conjurar la situación de anormalidad, debe avalarse la pertinencia técnica basada en la evidencia científica de las medidas por tomar, de manera que no acentúen las desigualdades existentes en la sociedad y que no deformen la Constitución.

3. No es confiable la dispersión normativa y la falta de divulgación pública para acceder a la informalidad de esta información puede ser perjudicial. Acceder a la información jurídica, aunque no sabemos cuánto dure el aislamiento, sí sabemos que el Covid-19 es una realidad que perdurará y, por tanto, debe el legislador empezar a cumplir sus funciones normativas para conjurar esta crisis y no solo dejar las medidas en cabeza del ejecutivo.

23 La Ley 137 de 1994 establece en su artículo $7^{\circ}$ que "en ningún caso se podrá afectar el núcleo esencial de los derechos fundamentales. El Estado de Excepción es un régimen de legalidad y por lo tanto no se podrán cometer arbitrariedades so pretexto de su declaración. Cuando un derecho o una libertad fundamentales puedan ser restringidos o su ejercicio reglamentado mediante decretos legislativos de Estados de Excepción, estos no podrán afectar el núcleo esencial de tales derechos y libertad".

24 La Ley 137 de 1994 establece en su artículo 16: "El deber de Información a los Organismos Internacionales: De acuerdo con el artículo 27 de la Convención Americana de los Derechos Humanos y el artículo $4^{\circ}$ del Pacto Internacional de Derechos Civiles y Políticos, al día siguiente de la declaratoria del estado de excepción, el Gobierno enviara al Secretario General de la Organización de Estados Americanos y al Secretario General de las Naciones Unidas, una comunicación en que de aviso a los Estados Partes de los tratados citados, de la declaratoria del estado de excepción, y de los motivos que condujeron a ella. Los decretos legislativos que limiten el ejercicio de derechos, deberán ser puestos en conocimiento de dichas autoridades. Igual comunicación deberá enviarse cuando sea levantado el estado de excepción". 
4. Promover el debate público respecto de las medidas que está tomando el Gobierno, por ejemplo, el traslado de pensiones a Colpensiones; la posibilidad de que autoridades de la rama reorienten la renta y la reducción de la tarifa de impuestos territoriales; la suspensión de términos judiciales; la limitación del control político, no solo del Congreso, sino también de los concejos municipales y asambleas departamentales, a los alcaldes y gobernadores, entre otras medidas.

Como dice explícitamente la Resolución 01 de 2020 de la Comisión Interamericana de Derechos Humanos, el "objetivo de todas las políticas y medidas que se adopten, deben basarse en un enfoque de derechos humanos, garantizar la igualdad y no la discriminación, la perspectiva de género, diversidad e interseccionalidad, la inclusión y la rendición de cuentas”. (Garzón, 2020).

\section{Posición del ministerio de justicia y del derecho de Colombia}

Desde el Gobierno Nacional se plantearon una serie de posiciones frente a la relación entre el poder ejecutivo y los demás sectores del Estado. Es así como la viceministra de justicia de Colombia (López, 2020), expone, en primer orden, que el ejecutivo asume un respeto irrestricto a la separación de las ramas del poder público, especialmente a las decisiones que le corresponde tomar a la rama judicial en el marco de la independencia y autonomía sobre el manejo de la crisis en los procesos judiciales. En el marco de ese respeto, la rama judicial, por medio del Consejo Superior de la Judicatura (C. S. de la J.), ha venido tomando las decisiones que le faculta la Ley Estatutaria de Administración de Justicia sobre el cierre de despachos judiciales, la continuidad de ciertos procesos y la suspensión de términos judiciales sin perjuicio de la colaboración armónica que establece la Constitución.

Razón por la cual el Gobierno ha venido haciendo sugerencias constructivas a la rama judicial para que el C. S. de la J. las tenga en cuenta en las decisiones que vaya adoptando sobre estos asuntos ponderando la importancia de la garantía de los derechos a la salud y a la vida tanto de los servidores judiciales como de los ciudadanos, pero al mismo tiempo tratando de garantizar el acceso a la administración de justicia (López, 2020) 25 .

25 En este mismo sentido, el viceministerio de Justicia hace referencia al marco normativo que profirió el Gobierno Nacional mediante los decretos legislativos "que escapan de las facultades ordinarias que tiene la rama judicial en cabeza del Consejo Superior de la Judicatura, pero que resultan 
El ejecutivo manifiesta que está tomando las medidas por medio de los decretos legislativos donde se pondera el derecho a la vida sobre la movilidad, lo que está bien sustentado, y por ello determina que debe decretarse un aislamiento preventivo, que recae en mayor medida sobre los trabajadores públicos de la rama judicial, esto es lo que tenemos y es incontrovertible; pero no se puede desconocer que el Gobierno actúa solo en el procedimiento de expedición normativa, sin consultar, sin coordinar, sin mediar en el esquema jurídico de la ley estatutaria de la administración de justicia. Por lo tanto, no es de buen recibo atribuir responsabilidad a la rama judicial por motivos de restricción y cierre de los servicios de administración de justicia, en cabeza del Consejo Superior de la Judicatura, bajo el supuesto respeto a la independencia de las ramas del poder, o la autonomía que les asiste en la separación de dichos poderes públicos; confundiendo los principios de la colaboración armónica con la ponderación constitucional de la garantía a la vida frente al recién creado aislamiento obligatorio, que es un confinamiento social, aplicado también a los funcionarios de justicia, sin una valoración científica, un acondicionamiento técnico y logístico en las instalaciones para continuar con la prestación del servicio judicial.

Ahora bien, el problema jurídico estriba en que, si los funcionarios de la rama judicial se encuentran en aislamiento obligatorio, en sus respectivas casas de habitación, sin un esquema jurídico y logístico para migrar a la virtualidad la estructura procesal y el andamiaje institucional de la justicia, no se podrían ejercer los respectivos controles, especialmente constitucionales y administrativos. Es decir, que acá se están confundiendo los valores fundamentales del derecho con los instrumentos que se deben adoptar para garantizar dichos derechos, vulnerando preceptos democráticos fundamentales. El Gobierno yerra mayúsculamente al mostrarse poco preparado e inexperto en la adopción de la razón y el juicio responsable que un buen padre de familia debe asumir en la administración ${ }^{26}$.

indispensables para la garantía de los derechos de los ciudadanos frente a la justicia”, lo cual se refleja en los decretos: 457 del 22 de marzo de 2020; 487 del 27 de marzo de 2020; 491 del 28 de marzo de 2020; 531 del 8 de abril de 2020; 564 del 15 de abril de 2020; 593 del 20 de abril de 2020; 636 del 6 de mayo de 2020; 689 del 22 de mayo de 2020; 749 del 28 de mayo de 2020.

26 Es de recordar que al gobierno le asiste la responsabilidad leve que determina el artículo 63 del Código Civil colombiano cuando hace referencia al cuidado que los hombres emplean ordinariamente en sus negocios propios. 


\section{Responsabilidad del Estado legislador}

Para abordar la responsabilidad del Estado legislador desde la óptica del poder ejecutivo en ejercicio de las prerrogativas que le confieren los estados de excepción constitucionales ${ }^{27}$, es menester abordar el marco jurídico de responsabilidad del Gobierno Nacional que determina la Ley Estatutaria 137 de 1994, "por la cual se regulan los estados de Excepción en Colombia”, cuyo artículo 52 establece la responsabilidad en cabeza del presidente de la República, de los ministros, funcionarios y agentes del Gobierno, cuando declaren el Estado de excepción sin lugar a ello, o que en el marco de ellos comentan abusos y extralimitaciones, donde para tal efecto "regirán las disposiciones constitucionales y legales sobre responsabilidad política, civil, administrativa y penal”. Igualmente, determina que en los decretos respectivos serán establecidas las medidas, sistemas y procedimientos que impidan o eviten excesos en la función que corresponde cumplir a los representantes o agentes gubernamentales (Ley 137 de 1994, art. 52).

Cuando el Gobierno Nacional está revestido de plenas facultades para la expedición de decretos con fuerza de ley, o los denominados decretos legislativos como los califica el capítulo 6, del título VII constitucional sobre los estados de excepción, estamos ante un poder ejecutivo con funciones propias del Congreso de la República, en cuanto a su producción legislativa, luego la consideración que hay que denotar es que está igualmente en posición de responder por sus actos en materia de órgano legislador. Es acá donde se configura una conexidad entre la ley estatutaria que regula el artículo 215 constitucional frente a los estados de emergencia económica, social y ecológica, lo cual en materia de responsabilidad se sujeta a la cláusula general de responsabilidad estatal consagrada en el artículo $90^{28}$ de la Carta. Así las cosas, en la teoría es evidente que existe una arquitectura jurídica para hacer valer el juicio de responsabilidad consagrado en el ordenamiento colombiano. Pero en la práctica,

27 Véase título VII, capítulo 6, artículos 212, 213 y 215 de la Constitución Política de Colombia.

28 El artículo 90 de la Constitución Política de Colombia establece que "el Estado responderá patrimonialmente por los daños antijurídicos que le sean imputables, causados por la acción o la omisión de las autoridades públicas", bien sea de orden extracontractual, precontractual y contractual. De igual manera, el artículo 1 de la Constitución regula la forma y carácter del Estado. Los artículos 2, 6 y 133, que consisten en irradiar sus actuaciones con el fin de promover la prosperidad general y garantizar la efectividad de los principios y deberes consagrados en la constitución, señalan la responsabilidad de los particulares y los servidores públicos conviniendo que estos respondan por sus omisiones y por extralimitación en sus funciones, deduciéndose que si sus actuaciones no se ciñen a las reglas o parámetros que rige un Estado de derecho como el principio de legalidad pueden incurrir en 
se contraponen una serie de condicionamientos que no permiten sostener un juicio de valor real, por cuanto los sistemas de imputación en materia de responsabilidad administrativa siguen siendo una mera expectativa para el desarrollo jurisprudencial, bajo el entendido de que no se tiene certeza sobre cómo abordar los instrumentos jurídicos para salvaguardar la institucionalidad y las garantías de los ciudadanos cuando estamos ante una responsabilidad del legislador, o quien haga sus veces, $y$, peor aún, si se acumulan todos los hechos derivados de una catastrófica pandemia que tiene al país presa del pánico y el terror.

Recordemos que el centro de la preocupación en que nos encontramos deriva en la concentración de poderes del ejecutivo, quien no optó por hacer las cosas en derecho o, por lo menos, con las reglas que dictamina la sana lógica jurídica, frente a llamar un consenso para legislar para el presente y el futuro con la certeza absoluta de que la pandemia se va a quedar instalada en el tiempo y en lo sucesivo puede mutar o que lleguen nuevas cepas del coronavirus. Entonces, por lógica, es deber construir un marco normativo especial, con carácter de norma legislativa extraordinaria para convalidarla con el Congreso mediante un "marco jurídico de pandemias" (Uprimny, 2020); pero, por el contrario, el gobierno optó, en razón de sus facultades legislativas excepcionales, por decretar un aislamiento general de todas las instituciones, órganos y poderes públicos que deberían estar coordinados para resolver la crisis de consuno.

Así las cosas, conforme los principios del derecho, podemos colegir que este no solo se constituye de normas de derecho positivo, sino que también lo integran principios generales que pueden ponderarse, como los derechos humanos, de ahí que una norma pierde su contenido cuando viola garantías fundamentales consagradas en tratados internacionales de derechos humanos y ratificadas en el ordenamiento interno, lo que la hace plenamente inválida, sin que produzca ningún efecto jurídico, puesto que la conexión entre el derecho y la moral está directamente relacionada con los estándares morales (Fajardo, 2014).

Lo que por fuerza nos introduce en el debate académico sobre la teoría constitucional alemana del derecho público, frente al control de convencionalidad,

responsabilidades Por otra parte, están las normas que en su mismo contenido prevén los daños antijurídicos que comportan y que, por tanto, deben ser indemnizados a los particulares por lesionar sus intereses patrimoniales de carácter ilícito (Ruiz, 2017). 
consagrada en la fórmula de Radbruch $(1946)^{29}$, en la que se dicta que ciertamente el legislador puede expedir normas extremadamente injustas, las cuales pueden crear sistemas jurídicos carentes de toda naturaleza del derecho; pues el defecto no es solo moral, sino que el defecto moral se transforma en un defecto jurídico. De esta forma, los gobiernos tiránicos y las decisiones extremadamente injustas de los jueces pierden validez moral y jurídica. Así, para Alexy (2001), quien defendió la teoría de Radbruch, manifiesta que las normas deben presentar criterios relacionados con la validez legal, la validez social y la validez moral, teniendo en cuenta que lo lícito en el derecho positivo debe seguir siendo lícito siempre y cuando no quebrante principios fundamentales de la justicia y del Estado de derecho ${ }^{30}$; entre tanto, Kelsen expresa que solo respecto del monarca se mantuvo siempre el principio de su irresponsabilidad como jefe del poder ejecutivo, no pudiendo, por tanto, ser responsable ante el legislativo, especialmente el parlamento, por lo cual necesitaba ser en absoluto independiente de este. Este principio, juntamente con el de la separación de poderes, fue aplicado a los Estados republicanos ${ }^{31}$.

Esto puede llevar a un revés en la institucionalidad democrática de un país que se ha consolidado en el marco del Estado constitucional de derecho con pleno respeto por los principios fundamentales, lo cual se puede ir al traste mediante un desbordamiento de competencias desde el ejecutivo, como se vivió en países europeos de los años cuarenta cuando se desinstitucionalizaron Estados referentes en modelos jurídicos y económicos, pero que inevitablemente se precipitaron al totalitarismo subsumido en el retroceso jurídico, sin pilares democráticos, sin separación de poderes públicos, sin controles ni contrapesos, sin colaboración armónica, sin garantía de derechos fundamentales, sin estabilidad jurídica, sin carta constitucional establecida y, mucho menos, sin quién responda. Posterior a la Segunda Guerra

29 Bajo la tesis del profesor Radbruch, "el derecho extremadamente injusto no es derecho", como lo expresa en su artículo Manuel Rello Varas (2019), "La fórmula Radbruch sobre el derecho extremadamente injusto", revista Standum est Chartae.

30 Para Rober Alexy (2001), se entiende que la inclusión o exclusión de elementos morales es necesaria para satisfacer determinadas normas que desarrollan valores como los derechos humanos; para Radbruch, la vulneración de los derechos humanos representa una injusticia extrema. Publicado en el artículo "Una defensa de la fórmula de Radbruch", del Anuario de la Facultad de Dereito de la Universidad de la Coruña. Recuperado de: https://ruc.udc.es/dspace/bitstream/handle/2183/2109/ AD-5-4.pdf? sequence=1\&isAllowed=y

31 Hans Kelsen, en 1925, afirmaba que los actos de gobierno del monarca iban ligados a la cooperación de los ministros como órganos superiores de la administración, y estos eran responsables ante el parlamento (responsabilidad ministerial), en el marco de la independencia de los órganos (Kelsen, 2004). 
Mundial, el derecho francés y especialmente el español nos ayudaron a entender que se debía ser más incisivo en el control y la responsabilidad ${ }^{32}$ frente al diseño de instrumentos universales de respeto por los derechos humanos; a contrario censu, los vencidos y maltrechos países totalitarios de la posguerra, como Alemania e Italia, no perseveraron en el enjuiciamiento de responsabilidad legislativa.

De igual forma, no es fácil desvirtuar los argumentos subjetivos esgrimidos desde el legislador frente a una eventual responsabilidad estatal por medio de la producción legal, donde se han opuesto argumentos de soberanía, autorregulación, democracia representativa, inexistencia de control de legalidad, petrificación de la labor legislativa, entre otras muchas, las cuales, bajo la órbita de responsabilidad, deben observarse sin perder el oriente que la estabilidad institucional y jurídica de todo el Estado pasa por contar con actos responsables, y más aun cuando excepcionalmente otro poder público se pone en una posición nueva donde no tiene experiencia pero quiere actuar solo y sin control.

Igual criterio encontramos en la doctrina española, por medio de la obra del profesor García de Enterría (2015), quien aborda el problema de la imputación a la administración derivada de los daños producidos por el hecho de las leyes, aunque pareciera que en principio dicha responsabilidad, más que patrimonial, se convierte en responsabilidad política, por cuanto la ley se encuentra en la base democrática

32 Jinesta Lobo expresa que en la república francesa de mediados de siglo xIX, con el fallo de Duchatelier de enero 11 de 1838 del Consejo de Estado, dicha corporación puntualizó que el Estado no debe ser responsable por las consecuencias de las leyes que en aras del interés general prohíben el ejercicio de una industria. Del Estado no pueden reclamarse otros créditos más que los urgidos de un contrato, de una disposición expresa y formal de la propia ley, inspirados en la doctrina de la Ferrière y Rousseau sobre la ley como expresión de la voluntad popular, fruto del contrato social. No podría atribuírsele responsabilidad al pueblo por la ley que se promulga en su nombre; aunado a ello, se concebía la posibilidad de una responsabilidad por la ley contraria a la Constitución, pero no existía control constitucional ni órgano competente para dicha tarea, de modo que era inadmisible la declaratoria de una indemnización. En el derecho español, la cláusula general de responsabilidad constitucional no está redactada bajo la acepción de autoridades públicas como sí ocurre en nuestro sistema jurídico colombiano en el artículo 90 constitucional; sino bajo la acepción de servicios públicos, lo cual restringe en un primer momento al legislador como sujeto de responsabilidad, toda vez que en la noción de servicios públicos no se incluye la actividad legislativa que representa la voluntad soberana, sino aquella que está orientada a satisfacer necesidades de los seres humanos, por ejemplo, servicios de telecomunicaciones, de energía, de salud, entre otros. En España, el control de discrecionalidad del legislador se realiza mediante el recurso de inconstitucionalidad reservado al tribunal constitucional y la declaratoria de inconstitucionalidad se convertirá en la única posibilidad de declarar la responsabilidad patrimonial del parlamento. De otra parte, se presentó la creación de instituciones de control para legislaciones de Estados vencidos en la guerra mundial que no poseían dichos parámetros de protección fundamental, entre ellos, Alemania e Italia. Mientras que en EE. UU. y en Inglaterra no se cuenta con dicha responsabilidad (Ruiz, 2013). 
que descansa en el principio de que los titulares del poder público lo ejercen como "fiduciarios del pueblo", quien es el titular real, a quien los funcionarios deben dar cuenta $^{33}$, y por tanto aducen argumentos de inmunidad por mérito de la producción legislativa en nombre del pueblo.

Anteriormente se podía accionar contra el Estado legislador por vía de una demanda indemnizatoria, siempre que se configuraran los presupuestos procesales de imputación, daño antijurídico y nexo causal, bajo dos motivos: se probara la expedición de leyes declaradas inconstitucionales, o por tratarse de una falla del servicio. Es decir, que se podría exigir la responsabilidad del Estado legislador, en primera medida, porque este profirió leyes o actos legislativos declarados inexequibles, por vía del título de imputación de falla del servicio, y, en segunda medida, encontramos la expedición de leyes exequibles, pero que vulneran la igualdad ante las cargas públicas de un administrado al desconocer sus derechos adquiridos, lo cual motiva la imputación objetiva (por daño especial) en la imputación al Estado dañoso infligido a los particulares.

\section{El Gobierno Legislador}

Posteriormente y hasta la actualidad, se viene desarrollando un significativo precedente frente a la tesis de inmunidad estatal por el ejercicio de la función legislativa, donde el Consejo de Estado está sentando jurisprudencia sobre la responsabilidad del Estado legislador, lo que deja abierta la puerta en la evolución jurisprudencial para revisar los casos del Gobierno Legislador que violente derechos fundamentales por adopción de medidas coercitivas sin acatamiento a la Constitución o la leyes estatutarias en ejercicio de decretos legislativos. Esto eventualmente conllevaría un juicio de responsabilidad al Gobierno por vía de reparación directa de las víctimas, como lo venimos observando conforme el aumento ostensiblemente en las acciones judiciales indemnizatorias por acción u omisión de la función legislativa del Congreso de la República, artículo sexto de la Ley quinta de 1992, el cual es responsable del desarrollo (u omisión) de sus funciones, constituyente, legislativa y de control político (Asuntos Legales, 2016).

33 García de Enterría y Fernández (2015) abordan el tema de la responsabilidad patrimonial del Estado por el hecho de las leyes declaradas inconstitucionales, responsabilidad la cual debe "admitirse, salvo que se hubiera producido una sentencia firme desestimatoria, en cuyo caso la indemnización solo podrá otorgarse al recurrente que se hubiese mostrado beligerante frente a la inconstitucionalidad de la ley en el curso del proceso". 
Es de recordar que el tránsito de un Estado legal de derecho a un Estado constitucional de derecho implica el sometimiento al principio de legalidad, que no es ajeno a la función estatal en la producción normativa orientada al afianzamiento y preservación del orden social, con pleno respeto por el "control sobre situaciones que afectan el orden público, social y económico o sobre las mismas actuaciones de los particulares" ${ }^{34}$ (Ulloa, 2018a).

Lo anterior se puede observar mediante la sentencia hito C-587 del 12 de noviembre de 1992 proferida por la honorable Corte Constitucional colombia$\mathrm{na}^{35}$, en la cual se traza la línea jurisprudencial de mayor significancia en materia de responsabilidad del Estado legislador frente a la aplicación y protección de los derechos fundamentales, siendo la ley que los vulnere o desconozca inexequible al paso del examen constitucional. De este modo, la responsabilidad patrimonial del Estado por los hechos, acciones u omisiones imputables al poder legislativo está expresamente contemplado en el artículo 90 de la Constitución, toda vez que esta sentencia abre la puerta por analogía entre la responsabilidad predicable al Estado legislador y aquella relacionada con el Gobierno Legislador mediante estados de excepción, como es el caso en estudio.

En consecuencia, se deben tener claros los supuestos de responsabilidad del Estado Legislador, mediante la posición de la Corte Constitucional y el Consejo de Estado fijada en la Sentencia C-038 de $2006^{36}$, en la cual se decidió sobre la exequibilidad del artículo 86 del anterior Código Contencioso Administrativo (ccA $)^{37}$ de 1984, donde se revisó la figura de acción de reparación directa, por cuanto el accionante consideró que estaba en contravía de lo dispuesto por el artículo 90

34 Conclusiones del artículo de Ulloa (2018a), "Otra mirada a la responsabilidad del Estado frente al lavado de activos y la captación masiva y habitual de dineros del público". Recuperado de https://revistas.usantotomas.edu.co/index.php/iusta/article/view/4644/4346

35 Es de resaltar que la Sentencia C-587 de 1992 determina que el Estado legislador debe dar eficacia a los derechos fundamentales. Es así como el Estado social de derecho está obligado a la protección de los derechos humanos en su condición objetiva, es decir, sus condiciones reales al interior de la sociedad y no en el contexto subjetivo del individuo en abstracto (Sentencia C-587 de 1992).

36 Proferida por la honorable Corte Constitucional con ponencia del magistrado Humberto Sierra Porto. En dicho fallo, la Corte analizó el alcance del artículo 90 constitucional, enfocándolo a la responsabilidad del poder legislativo, analizó la naturaleza de la acción de reparación directa y las clases de omisiones legislativas existentes, y declaró que en el caso bajo estudio no es de recibo aceptar la omisión legislativa relativa, toda vez que los hechos y omisiones deben entenderse producidos por autoridades administrativas como el órgano del poder legislador.

37 Entiéndase el Código Contencioso Administrativo colombiano (ccA), adoptado mediante el Decreto 01 de 1984. 
de la carta, bajo el entendido de que esta disposición no daba lugar para accionar por medio de control de reparación directa la responsabilidad del Estado legislador. Igualmente, se reiteró que la Corte solo puede pronunciarse frente a las configuraciones relativas, mas no absolutas (Ruiz, 2017).

En ese sentido, la Corte manifiesta que la responsabilidad del Estado legislador no solo se circunscribe a ciertos eventos como la declaratoria de inconstitucionalidad de una ley o la declaración de expropiación de un bien o la constitución de un monopolio o los temas atinentes a la reserva de la prestación del servicio público; pues, más allá de esto, la línea jurisprudencial adoptó la tesis del daño antijurídico posterior a la Carta de 1991, donde, según la manifiesta la doctrina y jurisprudencia, el elemento denominado culpa fue desplazado por la adopción de la teoría del daño antijurídico como fuente principal de imputación, ampliamente estructurada por el jurista y doctrinante Juan Carlos Henao (2007), quien aborda la concepción de daños originados por una falla del servicio, por acción u omisión de las autoridades públicas; si bien no se habla de culpa, sí se prescribió constitucionalmente el daño antijurídico como cláusula general de responsabilidad constitucional que un particular no está en el deber de soportar.

Por consiguiente, la posición responsable estatal debe observar el daño antijurídico, como lo manifiestan la tesis administrativista de Koteich (2012), siempre que esté "constituido por el hecho o acontecimiento objetivamente verificable que reside más allá del derecho" ${ }^{88}$; en consonancia con el profesor Wilson Ruiz, que agrega el elemento de la "culpa" para entrar a configurar la responsabilidad del Estado por el hecho de la ley bajo el siguiente tenor:

Estamos bajo la concepción de la teoría Organicista del Estado, donde hablamos de una responsabilidad anónima de la administración o de la culpa anónima, no de la culpa del agente. Bajo la teoría organicista, la culpa del agente viene a configurarse como la culpa del Estado. Suponer una falla en el servicio es suponer que existe una indebida diligencia o impericia por parte del órgano demandado, es suponer que existe una actuación por fuera de los cánones legales y constitucionales. (Ruiz, 2017)

38 Koteich Khatib, M. (2012), en su obra La reparación del daño como mecanismo de tutela de la persona, plantea la distinción entre el daño y el perjuicio haciendo alusión al Informe Lambert-Faivre. 
Lo anterior se debe revisar a la luz de la implicación que causan los presupuestos jurídicos de daño, culpa y nexo causal, así como la configuración del título de imputación válido frente a los regímenes de responsabilidad del Estado legislador aplicados al Gobierno Legislador de emergencia, por medio del cual se plantea una "yuxtaposición de regímenes", como lo determina el profesor Samuel Yong (2009), quien expresa en su obra que "la teoría subjetiva se plasmó como fundamento general de la responsabilidad en la mayoría de códigos civiles europeos, y por supuesto en latino americanos, coexisten actualmente con la teoría objetiva, la que por vía legislativa se ha venido implementando a través de disposiciones especiales”39, lo cual no podría ser de otra forma, en la medida que si la jurisdicción opta por acoger el título de imputación basado en la falla del servicio, inevitablemente debe revisar causales subjetivas de agentes públicos derivadas de actuaciones culposas, es decir, acogería un elemento subjetivo en la actuación legislativa, que no sería de buen recibo, cuando se revise a la luz del daño antijurídico.

\section{Régimen de imputación objetivo}

Con respecto al régimen de imputación administrativo que se viene empleando en estos casos, debemos anotar, que en palabras del profesor Saavedra (2011), se observa que la jurisprudencia actual "desplaza el fundamento de la responsabilidad administrativa, del concepto subjetivo de la antijuridicidad de la acción del Estado al concepto objetivo de la antijuridicidad del daño producido por ella" (Saavedra, 2011); en observancia de la Cláusula General de Responsabilidad Objetiva del artículo 90 constitucional, la cual incorporó los más modernos criterios sobre la materia de responsabilidad patrimonial del Estado, lo que indica, en palabras de los autores Alier Eduardo Hernández Enríquez y Catalina Franco Gómez (2007), que se objetivizó el concepto de daño antijurídico con fundamento en la doctrina española en concordancia con la entrada en vigor de la Constitución Colombiana de 1991.

Con base en lo anterior, debemos anotar que la objetivización del concepto de daño antijurídico sobreviene del equilibrio de las cargas públicas, bajo el entendido de la obligación de resarcir un daño antijurídico causado injustamente a una persona, en contraste con el raciocinio judicial subjetivo realizado por los jueces (basada en la culpa o falla del servicio) anterior a la "entrada en vigencia de la Constitución

39 Véase Yong, S. (2009). Introducción a la responsabilidad pública y privada. Bogotá D. C., Colombia: Colección Docencia y Derecho, Universidad Santo Tomás. 
de 1991", puesto que anteriormente no se contaba expresamente con un precepto objetivo constitucional de responsabilidad y, por lo tanto, estaba concebido como una "institución de origen netamente jurisprudencial", cuyos títulos de imputación dentro del ordenamiento jurídico interno se sustentaban en aspectos subjetivos de la falla del servicio, aunque en algunos casos, esporádicos y muy excepcionales, empleaban las figuras objetivas de daño especial o riesgo excepcional (Murillo y Ulloa, 2019).

Recientemente, en el año 2015 se vivió una evolución jurisprudencial del derecho administrativo, cuando la sección tercera del Consejo de Estado ${ }^{40}$ amplió su postura en materia de responsabilidad del Estado Legislador, admitiendo un título de imputación derivado de la defraudación del principio de confianza legítima ${ }^{41}$ en la medida que cause daños antijurídicos a los ciudadanos por fuerza de una ley que al ser declarada exequible conculque derechos adquiridos o situaciones jurídicamente consolidadas. Lo cual quiere decir que toda persona que se crea afectada en su ámbito patrimonial o extrapatrimonial estaría llamada a acreditar la existencia de daños antijurídicos infligidos a causa de aquellas modificaciones intempestivas e impredecibles que alteran su seguridad jurídica sin que se prevean medidas transitorias o compensatorias por parte del legislador dañoso, quien estará obligado a su reparación directa, así sea un hecho legal, "lo que nos pondrá ente un título de imputación por vía de régimen especial” (Ruiz, 2017).

De otra forma, no se explicaría la escasa judicialización del poder ejecutivo causante de daños antijurídicos por su extralimitación en funciones legislativas, advirtiendo una tensión entre el régimen subjetivo basado en la culpa mediante el título de imputación por falla del servicio, en lugar de aplicar el régimen de responsabilidad objetiva, puesto que, como ya anotamos, la primera no se adecúa a la protección efectiva de las víctimas, rompiendo con las cargas públicas y el inoportuno control, inspección y vigilancia estatal ${ }^{42}$ (Ulloa, 2018b).

40 Sentencia 2500023260001999000701 proferida por la Sección Tercera del Consejo de Estado de Colombia, expediente 22637, de fecha 31 de agosto de 2015, con ponencia del consejero Ramiro Pazos. Esta providencia, siguiendo la línea de la Subsección B, mediante Sentencia 27228 de 2013 proferida por el Consejo de Estado de Colombia, acepta que las expectativas legítimas y los estados de confianza se encuentran sujetos al control jurisdiccional administrativo.

41 La confianza legítima entendida como el principio que supone la imposibilidad de "adoptar medidas que resulten contrarias a la esperanza inducida por la razonable estabilidad de las decisiones administrativas tomadas, y en función de las cuales los ciudadanos han realizado determinadas actuaciones" (Cuadrado Zuloaga, 2009).

42 Se concluye del artículo "Marco jurídico del lavado de activos y de la captación masiva habitual de dineros desde un enfoque de derecho administrativo" (Ulloa, 2018b). 
En este caso de responsabilidad del Estado Legislador colombiano, es de subrayar que el poder jurisdiccional en cabeza del Consejo de Estado es el competente para escoger el camino por el cual resuelve los casos, en observancia del principio de Iura Novit Curia ${ }^{43}$ y recogido por la Sentencia C-333 de 1996 frente al daño antijurídico en ruptura de las cargas públicas, así se viene inclinando la jurisprudencia por la imputación objetiva basada en el daño especial, circunstancia que se acopla a los mecanismos de protección de los derechos fundamentales en el marco de la cidH en desarrollo de una línea jurisprudencial más estructurada, por tratarse de la aplicación del bloque de constitucionalidad que comprende tratados internacionales del mayor calibre ratificados por Colombia en el marco de los derechos humanos, y donde se debe estar muy atento en los daños causados por el concurso de los más encumbrados poderes púbicos: ejecutivo y legislativo.

De lo anterior se infiere que la responsabilidad del Estado legislador, por el hecho de expedir normas con fuerza de ley (o decretos legislativos excepcionales), se ha venido ampliando sustancialmente, bien por falla del servicio, daño especial, por desconocer las expectativas legítimas y el estado de confianza ${ }^{44}$ a la hora de expedir una ley, que como función pública es indemnizable, sin que se dé una posible inmunidad jurisdiccional en razón a la cual se crea en condición superior para vulnerar derechos sin conllevarle ninguna consecuencia.

\section{Conclusiones}

El temor a la pandemia no puede aumentar nuestra tolerancia frente a las restricciones de los derechos fundamentales y los derechos humanos que debe garantizar el Estado social de derecho. En la medida en que la actual crisis conculca derechos en materia de posibles abusos desde el punto de vista democrático; afectaciones de los principios de precaución y prevención, desde el punto de vista científico,

43 Por el aforismo latino del derecho: "el juez conoce el derecho".

44 Las expectativas legítimas son situaciones encaminadas a la formación de un derecho subjetivo, conformadas por aquellas esperanzas legítimas que surgen del ejercicio de la autonomía de la voluntad privada expresado en la constitución de los hechos previstos en la ley para la adquisición del derecho. Entre tanto, los estados de confianza son los que se crean en el ámbito del sujeto a partir de comportamientos uniformes del Estado que se caracterizan por ser actos objetivos y suficientemente concluyentes, que orientan al ciudadano hacia una determinada conducta y que deben tutelarse. En cuanto al estado de confianza, se podría pedir la indemnización por afectar la estabilidad laboral reforzada, en aplicación del principio de no regresividad del derecho (Asuntoslegales, 2016). 
y la vulneración de los derechos humanos, sociales y ambientales de los grupos vulnerables o grupos sin representación.

Fomentar exhaustivamente el fortalecimiento del ejercicio del control legal mediante la aplicación de mayores niveles de democracia deliberativa, mayor control político y transparencia social, cuando se vean omitidos, restringidos, limitados, anulados, transgredidos o conculcados los derechos fundamentales o los derechos humanos.

En consecuencia, se advierte que la jurisdicción debe garantizar que las medidas adoptadas corresponden a respuestas responsables, científicas, que conllevan la adopción de requerimientos técnicos y estructurales proporcionales a los hechos que requieren de la mayor diligencia y cuidado gerencial; siempre alejadas de reacciones teórico-discursivas, pasionales, viscerales, o producto de meros cálculos políticos que rompan los equilibrios constitucionales y atomicen el poder político central frente a las entidades territoriales. Por lo cual, como se ha iterado, no se puede permitir que el Gobierno Legislador limite o elimine el libre ejercicio de los derechos fundamentales, toda vez que dichos principios y derechos se constituyen como elementos esenciales de la vida en comunidad dentro del Estado constituido bajo los parámetros y reglas que los ciudadanos pactaron en el contrato social.

Los controles ejercidos por los poderes legislativo (control político del Congreso de la República) y judicial (ya sea por las cortes Constitucional y Consejo de Estado) deberían estar acompañados simultáneamente por filtros sociales, científicos y políticos para que alienten la fortaleza democrática, preservando los principios generales de los derechos humanos, los tratados internacionales en materia de principios fundamentales enmarcados en la carta constitucional, los preceptos fundantes del Estado social y democrático de derecho; previniendo que dichos controles no sean incipientes, deleznables o inexistentes, puesto que conllevaría la existencia de un jefe de Estado presidencialista revestido de los poderes legislativo, político y judicial, sentando un grave precedente para la salud de nuestro sistema democrático.

El Gobierno Legislador, bajo la expedición de decretos legislativos en uso de los poderes excepcionales que le confieren los estados de emergencia, no puede atribuir responsabilidad al Consejo Superior de la Judicatura por la restricción y cierre de los servicios de administración de justicia, pues se vulneran los derechos humanos, sociales y políticos en el marco del acceso a la justicia y la independencia de las ramas del poder público. 
Sí la única certeza científica que se ha establecido es que la pandemia llegó para quedarse sin ninguna veracidad concreta que determine cuánto tiempo tardará en controlarse, entonces lo más recomendable que puede hacer el Estado es no improvisar en normas sobre ensayo y error expedidas día a día. Lo más recomendable es que los poderes públicos y la vocería de la sociedad se convoquen democráticamente, puesto que no sienta buen precedente para la democracia que se legisle con instrumentos transitorios excepcionales una crisis que puede perdurar largo tiempo.

No es de buen recibo para la vida democrática del país, ni queda bien ante los organismos internacionales en materia de derechos fundamentales, que no se cuente con un gran diálogo democrático nacional en el seno del Congreso para revisar y aprobar las salidas a la crisis mediante un "marco legislativo para las pandemias", a manera de código nacional, que proporcione movilidad a los actores de la academia, el cuerpo científico y el mundo político en armonía con la rama jurisdiccional, en acatamiento de los preceptos internacionales consagrados en tratados sobre derechos fundamentales. Corresponde al legislador empezar a cumplir sus funciones normativas, puesto que no es confiable la dispersión normativa, las constantes reformas que por vía excepcionales perdurarán en el ordenamiento jurídico mediante decretos con fuerza de ley, sin debido control político y jurisdiccional.

Como conclusión de cierre tenemos por decir sobre la responsabilidad de la figura del Gobierno Legislador lo siguiente:

El Estado legislador es plenamente responsable de indemnizar los daños antijurídicos que cause por acción u omisión de la actividad legislativa.

El Gobierno Nacional, en uso de la declaratoria de estados de excepción, es plenamente responsable por los daños antijurídicos que cause a los administrados derivados de la materialización de su voluntad mediante decretos legislativos o decretos con fuerza de ley, en virtud de la emergencia, económica, social o ecológico o que constituya grave calamidad pública, conmoción interior o guerra exterior.

La jurisprudencia administrativa abrió el compás de los títulos de imputación (de los subjetivos como la falla del servicio y los objetivos basados en el daño especial) a las nuevas circunstancias derivadas del Estado legislador comprendidos en las expectativas legítimas y el estado de confianza a la hora de expedir una ley, extensivo por analogía al decreto con fuerza de Ley, o, en su defecto, un decreto legislativo, cuando el ejecutivo esté en uso de sus facultades excepcionales.

En materia de responsabilidad del Estado legislador (por analogía el Gobierno Legislador), la jurisprudencia administrativa se viene inclinando por la imputación 
objetiva basada en el daño especial en concordancia con los mecanismos de protección de los derechos fundamentales en el marco de la Corte Interamericana de Derechos Humanos, en desarrollo de una línea jurisprudencial más estructurada, por tratarse de la aplicación del bloque de constitucionalidad que comprende tratados internacionales del mayor calibre ratificados por Colombia en el marco de los derechos humanos.

\section{Referencias}

Agudelo, C. A. (2020). Debate constitucional sobre el control a los decretos de emergencia por Coronavirus. Videocolumna de Ámbito Jurídico. Legis. Recuperada de https://www.youtube.com/watch?v=eErzfYnKCUs\&feature=emb_title

Alexy, R. (2001). Una defensa de la fórmula de Radbruch. Anuario de la Facultad de Dereito. Universidad de la Coruña. Recuperado de https://ruc.udc.es/dspace/bitstream/ handle/2183/2109/AD-5-4.pdf?sequence=1\&isAllowed=y

Asuntos Legales (2016). Responsabilidad del Estado Legislador. La República. Recuperado de https://www.asuntoslegales.com.co/opinion/responsabilidad-del-estadolegislador-2409471

Brito Ruiz, F. (2013). Estructura del Estado colombiano y de la administración pública nacional, según la Constitución de 1991. Revaluación de conceptos constitucionales y administrativos. Bogotá D. C., Colombia: Legis.

Comisión Interamericana de Derechos Humanos. (10 de abril de 2020). Resolución 01 de 2020 por la cual se formulan recomendaciones a los Estados Miembros en materia de Pandemia y derechos humanos en las Américas. Recuperado de http://www.oas.org/ es/cidh/decisiones/pdf/Resolucion-1-20-es.pdf

Consejo de Estado. (31 de agosto de 2015). Sección Tercera. Sentencia 2500023260001999000701. Expediente 22637. C. P. Ramiro Pazos.

Constitución Política de Colombia. (20 de julio de 1991). Congreso Nacional Constituyente.

Correa, M. (2020). Debate constitucional sobre el control a los decretos de emergencia por Coronavirus. Videocolumna de Ámbito Jurídico. Legis. Recuperado de https://www.youtube.com/watch?v=e7RHPousbfo\&feature=emb_title 
Corte Constitucional. (12 de noviembre de 1992). Sala Plena. Sentencia C-587, expediente D-055. [M. P. Ciro Angarita Barón].

Corte Constitucional. (01 de agosto de 1996). Sala Plena. Sentencia C-333, expediente D-1111. [M. P. Alejandro Martínez Caballero].

Corte Constitucional. (24 de abril de 1997). Sala Plena. Sentencia C-212, expediente D-1472. [M. P. Carmenza Isaza de Gómez].

Corte Constitucional. (01 de febrero de 2006). Sala Plena. Sentencia C-038, expediente D-5839. [M. P. Humberto Antonio Sierra Porto].

Corte Suprema de Justicia. (1979). Gaceta Oficial n. ${ }^{\circ} 2401$ de la Corte Supera de Justicia. Tomo CLX, Jurisprudencia Constitucional. Recuperado de http://www.cortesuprema. gov.co/corte/wp-content/uploads/subpage/GJ/Gaceta\%20Judicial/GJ\%20CLX\%20 n.\%202401\%20(1979).pdf

Cuadrado Zuloaga, D. (2009). Vulneración del principio de confianza legítima. Actualidad administrativa, 18, 3. Recuperado de http://dialnet.unirioja.es/servlet/ ejemplar? codigo $=233630$

Fajardo, Z. (2014). La fórmula de Radbruch y el Control de Convencionalidad. Nexos, el juego de la Suprema Corte. México. Recuperado de https://eljuegodelacorte.nexos.com. mx/?p=3911\#: :text=Como\%20testigo\%20destacado\%20de\%20su,puede\%20hacer\%20 leyes\%20extremadamente\%20injustas.

García de Enterría, E. y Fernández, T. (2015). Curso de derecho administrativo II. Madrid, España: Editorial Civitas.

Garzón Zuluaga, A. L (2020). Debate constitucional sobre el control a los decretos de emergencia por Coronavirus. Videocolumna de Ámbito Jurídico. Legis. Recuperado de https://www.youtube.com/watch?v=7J0PCzkOlYw\&feature=emb_title

Henao, J. C. (2007). El daño. Análisis comparativo de la responsabilidad extracontractual del Estado en derecho colombiano y francés. Bogotá D. C., Colombia: Editorial Universidad Externado de Colombia.

Hernández Henríquez, A. E. y Franco Gómez, C. (2007). Responsabilidad extracontractual del Estado. Análisis de la jurisprudencia del Consejo de Estado. Bogotá D. C., Colombia: Editorial Nueva Jurídica. 
Hoyos Ceballos, E. (2020). Debate constitucional sobre el control a los decretos de emergencia por coronavirus. Videocolumna de Ámbito Jurídico. Legis. Recuperado de https://www.youtube.com/watch?v=A86c0_QFEFs\&feature=emb_title

Kelsen, H. (2004). Teoría general del Estado. Función politica de la teoría; fundación de la monarquía constitucional. Ciudad de México: Ediciones Coyoacán.

Koteich, M. (2012). La reparación del daño como mecanismo de tutela de la persona. Bogotá D. C., Colombia: Editorial Universidad Externado de Colombia

López, J. (2020). Distintos puntos de vista sobre la reactivación de la justicia en las sedes judiciales. Videocolumna de Ámbito Jurídico. Legis. Recuperado de https://www.youtube. $\mathrm{com} /$ watch?v=V8om-EklxIo\&feature=emb_title

Murillo, M. y Ulloa, L (2019). La omisión administrativa como fuente de la responsabilidad extracontractual del Estado. Bogotá D. C., Colombia: Grupo Editorial Ibáñez.

Organización de Naciones Unidas. (3 de abril de 2020). “Coronavirus: ¿llegó para quedarse?”. Recuperado de: https://www.unenvironment.org/es/noticias-y-reportajes/reportajes/ coronavirus-llego-para-quedarse

Palacios, A (2020). Debate constitucional sobre el control a los decretos de emergencia por Coronavirus. Videocolumna de Ámbito Jurídico. Legis. Recuperada de: https://www.youtube.com/watch?v=269-JmU1Jnc\&feature=emb_title

Pérez Escobar, J. (2010). Derecho constitucional colombiano. Bogotá D. C., Colombia: Editorial Temis.

Preciado, D. (2008). Frases latinas del derecho usual. Bogotá D. C., Colombia: Librería Ediciones del Profesional Ltda.

Rello, M. (2019). La fórmula Radbruch sobre el derecho extremadamente injusto. Standum est Chartae. Revista digital del Real e Ilustre Colegio de Abogados de Zaragoza-Relcaz. Recuperado de http://revista.reicaz.es/n-016/la-formula-radbruch-sobre-el-derechoextremadamente-injusto/

Roa, J (2020). Debate constitucional sobre el control a los decretos de emergencia por Coronavirus. Videocolumna de Ámbito Jurídico. Legis. Recuperada de: https://www.youtube.com/watch?v=9-IC6boIIjY\&feature=emb_title

Ruiz, W. (2013). Responsabilidad del Estado y sus regímenes. Bogotá D. C., Colombia: Editorial Ecoe Ediciones. 
Ruiz,W. (2017). Responsabilidad del Estado Legislador en Colombia. Realización Audiovisual, Nproductions. Recuperado de https://www.youtube.com/watch?v=fACmXQW4HAU

Ulloa, L (2018a). Otra mirada a la responsabilidad del Estado frente al lavado de activos y la captación masiva y habitual de dineros del público. Revista IUSTA. IssN 2422-409 [online]. Recuperado de: https://revistas.usantotomas.edu.co/index.php/iusta/article/ view/4644/4346

Ulloa, L. (2018b). Marco jurídico del lavado de activos y de la captación masiva habitual de dineros desde un enfoque de derecho administrativo. Revista Virtual Via Inveniendi Et Iudicandi. VIeI, 13(2), 81-106 [en línea]. Recuperado de: https://revistas.usantotomas. edu.co/index.php/viei/article/view/4515/4236

Uprimny Yepes, R. (2020). Debate constitucional sobre el control a los decretos de emergencia por Coronavirus. Videocolumna de Ámbito Jurídico. Legis. Recuperada de: https://www.youtube.com/watch?v=TezHbN11ILc\&feature=emb_title

Velázquez, R. y Zimmerling, R. (2007). Robert Alexy, teoría del discurso y derechos constitucionales. Cátedra Ernesto Garzón Valdés. México D. F., México: Coyoacán.

Yong, S. (2009). Introducción a la responsabilidad pública y privada. Bogotá D. C., Colombia: Universidad Santo Tomás, Colección Docencia y Derecho.

Saavedra, R. (2011). La responsabilidad extracontractual de la administración pública. Bogotá D. C., Colombia: Grupo Editorial Ibáñez. 